\title{
A rare case of secondary abdominal pregnancy following ruptured rudimentary horn
}

\author{
Anju Sreenivas, Valsa Diana G.*
}

Department of Obstetrics and Gynecology, Rajiv Gandhi Government Women and Children Hospital, Puducherry, India

Received: 07 November 2020

Accepted: 16 December 2020

*Correspondence:

Dr. Valsa Diana G.,

E-mail: valsadiana@gmail.com

Copyright: (C) the author(s), publisher and licensee Medip Academy. This is an open-access article distributed under the terms of the Creative Commons Attribution Non-Commercial License, which permits unrestricted non-commercial use, distribution, and reproduction in any medium, provided the original work is properly cited.

\begin{abstract}
Abdominal pregnancies are classified as primary or secondary of which secondary abdominal pregnancies are more common. The incidence of abdominal pregnancy varies from 1 in 372 to 1 in 9,714 live births and accounts for $1.4 \%$ of ectopic pregnancies. Rudimentary horn pregnancy occurs in approximately 1/76 000 to $1 / 150000$ pregnancies. Abdominal pregnancies are classified as primary or secondary of which secondary abdominal pregnancies are more common. The incidence of abdominal pregnancy varies from 1 in 372 to 1 in 9,714 live births and accounts for $1.4 \%$ of ectopic pregnancies. Rudimentary horn pregnancy occurs in approximately 1/76 000 to 1/150 000 pregnancies.

We report a case of secondary abdominal pregnancy in a 24-year-old primigravida at 19 weeks gestation who was asymptomatic on admission but a known case of unicornuate uterus with rudimentary right horn. Ultrasound revealed fetus in the abdominal cavity and was confirmed by MRI. Intraoperatively, fetus was found en sac in abdominal cavity and placenta in the cavity of the ruptured right rudimentary horn which was removed in toto with the horn.
\end{abstract}

Keywords: Secondary abdominal pregnancy, Ruptured rudimentary horn, Abdominal radiography

\section{INTRODUCTION}

Abdominal pregnancies are classified as primary and secondary. Secondary abdominal pregnancies are the most common and result from tubal abortion or rupture or, from subsequent implantation within the abdomen after uterine rupture. The incidence of abdominal pregnancy varies from 1 in 372 to 1 in 9,714 live births and accounts for $1.4 \%$ of ectopic pregnancies. ${ }^{1,2}$

The presentation of patients with an abdominal pregnancy varies and depends on the gestational age. In the first and early second trimesters, the symptoms may be the same as tubal ectopic gestation; in advanced abdominal pregnancy, the clinical presentation is more variable. Diagnostic aids include abdominal ultrasonography, CT, MRI, abdominal radiography. ${ }^{3-5}$ Because the pregnancy can continue to term, the potential maternal morbidity and mortality are very high.
Unicornuate uterus with a rudimentary horn is a Mullerian duct malformation. The incidence of Mullerian duct malformations in the general population is estimated to be $4.3 \%$ while that of unicornuate uterus is about $0.4 \% .^{6}$ Rudimentary horn pregnancy occurs in approximately $1 / 76000$ to $1 / 150000$ pregnancies. $^{7,8}$

\section{CASE REPORT}

A 24-year-old primigravida presented to our hospital at 19 weeks and 3 days of pregnancy, referred from peripheral hospital as a case of unruptured chronic ectopic pregnancy.

Patient had history of treatment for primary infertility, but now conceived spontaneously, and, as a part of evaluation, underwent hysterolaparoscopy and a diagnosis of unicornuate uterus with rudimentary right horn was made. 
Her initial dating scan was normal with evidence of intrauterine gestation. At 15 weeks pregnancy, she had complaints of pain abdomen and bleeding per vaginum. She was admitted in a peripheral hospital and suspected to have cervical incompetence, prophylactic encirclage was done.

Now, on admission, patient was asymptomatic, vitals were stable, clinically not pale and afebrile. On per abdominal examination, fetal parts were superficially felt in the left hypochondrium, uterus not palpable, no other masses felt, free fluid, nor tenderness. Per vaginal examination, vagina healthy, cervix pointing downwards and cervical stitch visualized, same removed. There was no adnexal mass, cervical motion tenderness, no bleeding.

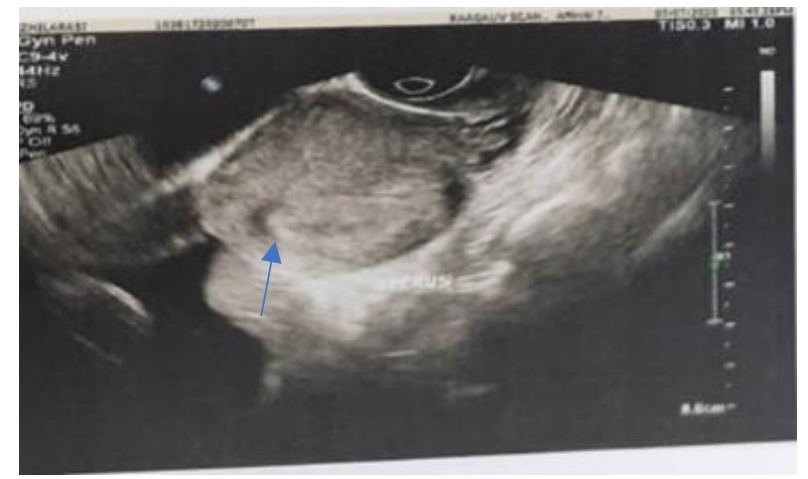

Figure 1: Uterus seen separately.

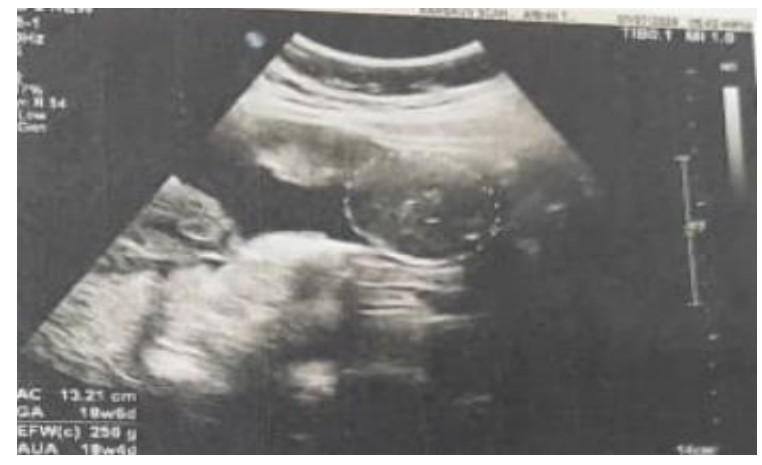

Figure 2: Fetus in sac in the abdominal cavity.

Further evaluation with USG abdomen and pelvis yielded a diagnosis of abdominal pregnancy with the following features like uterus and fetus separately visualized, foetus in abdominal cavity and placenta seen in? horn of the uterus.

Patient was subsequently taken up for exploratory laparotomy.

Intraoperative findings were like ruptured right rudimentary horn with placenta in the cavity of the right horn. Fetus weighing $270 \mathrm{gm}$ with amniotic sac in peritoneal cavity with cord communicating to the placenta. Amniotic band attached to sigmoid mesentery.

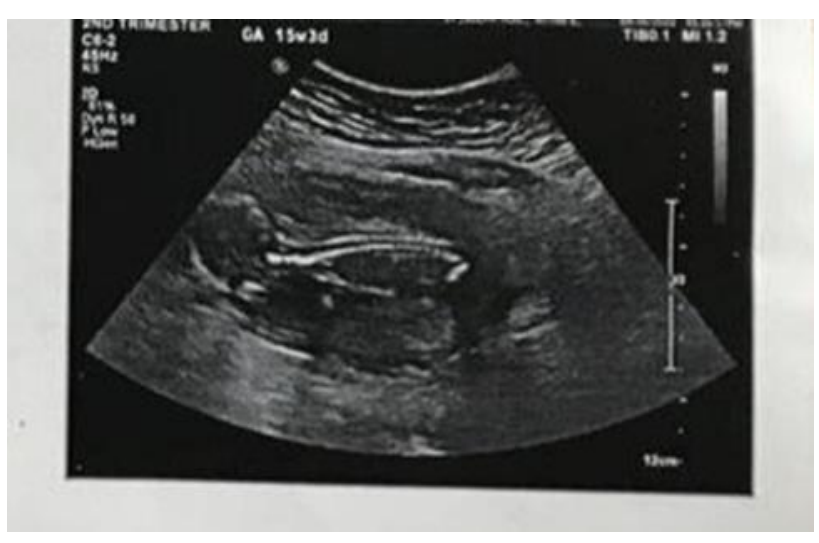

Figure 3: 15 weeks scan of intrauterine pregnancy, abdominal pregnancy (which may have been interpreted as intrauterine.)



Figure 4: Fetus visualized beneath rectus sheath.

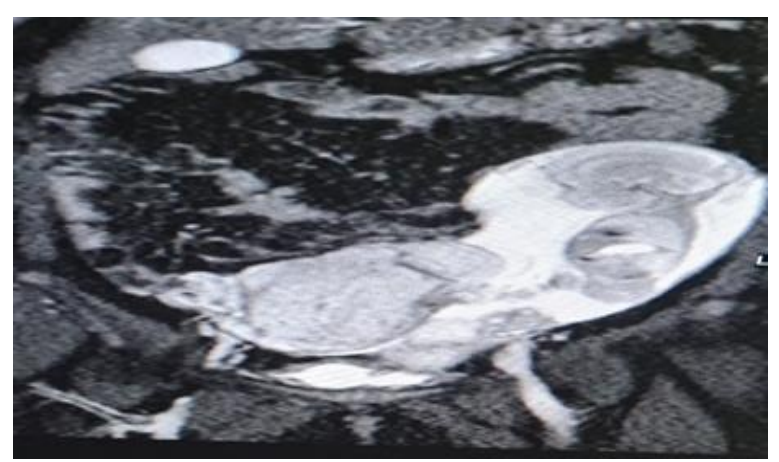

Figure 5: MRI of intra-abdominal gestational sac with fetus in left lumbar and pelvic region.

The ruptured rudimentary horn was removed along with the placenta. Amniotic band adherent to sigmoid mesentery removed. Drain kept and abdomen was closed. One unit packed red cell was transfused intra operatively. Immediate post-operative period was uneventful.

On post-operative day 7, suture removal was done, patient had wound gaping and wound re-suturing was done subsequently and patient discharged after adequate antibiotic coverage and wound care. 




Figure 6: (A and B) Fetus in the peritoneal cavity.

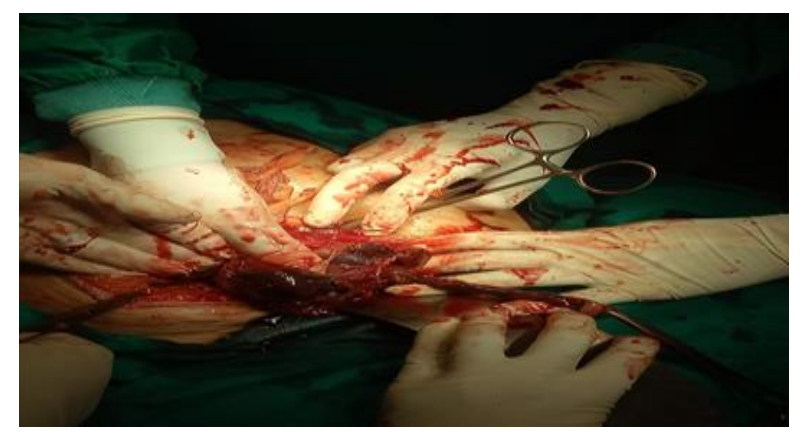

Figure 7: Placental attachment.

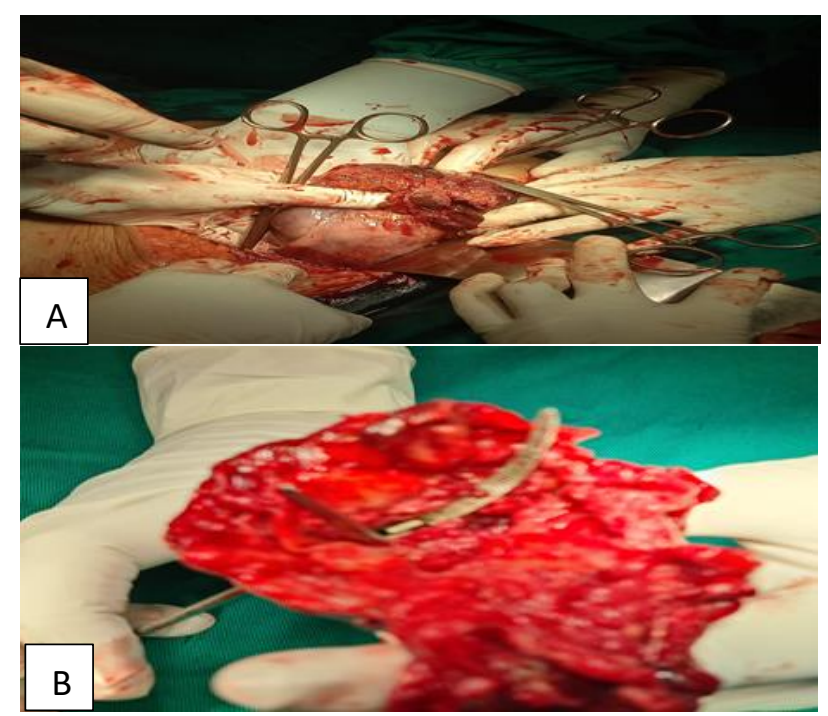

Figure 8: (A and B) Ruptured rudimentary horn.

\section{DISCUSSION}

First case of ruptured rudimentary horn pregnancy was described by Mauriceau in $1669 .{ }^{9}$

Diagnosis of abdominal pregnancy requires a high index of suspicion. History and physical examination are often inconclusive. Rudimentary uterine horn pregnancy usually ruptures during second or third trimester.
Ultrasonographic diagnosis made prior to rupture is the key to successful management of rudimentary uterine horn pregnancy. MRI has a high rate of diagnostic accuracy for Mullerian abnormalities. ${ }^{10}$

Our patient was asymptomatic on admission, but with prior history of unicornuate uterus. Clinical finding and USG gave suspicion of an abdominal pregnancy and was confirmed by MRI. The intra-operative findings confirmed a unicornuate uterus with a communicating type of rudimentary horn which could have probably ruptured at the time when she presented with painful abdomen and bleeding per vaginum at 15 weeks gestation.

She fortunately continued the pregnancy without significant hemorrhage. In our patient, the placenta was in the cavity of the ruptured rudimentary horn and partly exposed out. It was possible to remove the whole of the placenta along with the rudimentary horn to which it was attached without significant hemorrhage.

This case report has highlighted the need for high index of suspicion of an abdominal pregnancy in a known case of unicornuate uterus with rudimentary horn. The radiologist and obstetrician should be aware of such possibilities which could be missed sonographically and also should correlate with the clinical features in establishing early diagnosis and prompt treatment to prevent complications.

Similar case report by Rajshree et al, presented a primi at 28 weeks of gestation, presented with acute abdominal pain and distension with circulatory shock. Clinical and ultrasound findings were suggestive of abdominal pregnancy and possibility of rupture of one horn of bicornuate uterus. Laparotomy revealed abdominal pregnancy with dead foetus and ruptured right rudimentary horn. ${ }^{11}$

Another case report by Bansal et al, presented a gravida 2 Para 1 Live 1 with previous vaginal delivery who came with acute abdominal pain with clinical diagnosis of ruptured ectopic pregnancy. Laparotomy revealed ruptured rudimentary horn pregnancy with fetus in the abdominal cavity. Excision of rudimentary horn was done which was non-communicating. ${ }^{12}$

\section{CONCLUSION}

The presentation of a pregnant woman, who is a known case of anomalous uterus, especially with abdominal pain in association with bleeding or spotting per vaginum, should alert the obstetrician to the possibility of rupture subsequently leading to abdominal pregnancy. Prompt diagnosis and early intervention will help prevent the mortality and morbidity.

Funding: No funding sources Conflict of interest: None declared 


\section{Ethical approval: Not required}

\section{REFERENCES}

1. Bouyer J, Coste J, Fernandez H, Pouly JL, Job-Spira N. Sites of ectopic pregnancy: a 10-year populationbased study of 1800 cases. Hum Reprod. 2002;17:3224-30.

2. Atrash HK, Friede A, Hogue CJR. Abdominal pregnancy in the United States: frequency and maternal mortality. Obstet Gynecol. 1987;69:333-7.

3. Stanley JH, Horger EO, Fagan CJ, Andriole JG, Fleischer AC. Sonographic findings in abdominal pregnancy. AJR Am J Roentgenol. 1986;147:1043-6.

4. Harris MB, Angtuaco T, Frazer CN, Mattison DR. Diagnosis of a viable abdominal pregnancy by magnetic resonance imaging. Am J Obstet Gynecol. 1988;159:150-1.

5. Lockhat F, Corr P, Ramphal S, Moodley J. The value of magnetic resonance imaging in the diagnosis and management of extra-uterine abdominal pregnancy. Clin Radiol. 2006;61:264-9.

6. Grimbizis GF, Camus M, Tarlatzis BC, Bontis JN, Devroey P. Clinical implications of uterine malformations and hysteroscopic treatment results. Hum Reprod Update. 2001;7:161-74.
7. Ural SH, Artal R. Third-trimester rudimentary horn pregnancy. A case report. J Reprod Med. 1998;37:919-21.

8. Nahum GG. Rudimentary uterine horn pregnancy. A case report on surviving twins delivered eight days apart. J Reprod Med. 1997;42:525-32

9. Mauriceau F. Traite des maladaies des femme's grosses, Compaigne des libraries, Paris, France, $1721 ; 1$.

10. Tsafrir A, Rojansky N, Sela HY. Rudimentary horn pregnancy: first trimester pre-rupture sonographic diagnosis and confirmation by magnetic resonance imaging. J Ultrasound Med. 2005;24:219-23.

11. Katke RD, Raina J. Secondary abdominal pregnancy following rupture of bicornuate uterus in early third trimester. Int J Reprod Contracept Obstet Gynecol. 2013;2(3):454-7.

12. Bansal R, Somalwar S. Secondary abdominal pregnancy following rupture of rudimentary horn. Panacea J Med Sci. 2016;6(2):113-4.

Cite this article as: Sreenivas A, Diana VG. A rare case of secondary abdominal pregnancy following ruptured rudimentary horn. Int J Reprod Contracept Obstet Gynecol 2021;10:777-80. 